\title{
Commentary
}

\section{A Changeable Relation Between Alcohol and Life Expectancy in Russia}

$\mathrm{T}_{\mathrm{r}}^{\mathrm{H}}$ HE ARTICLE BY Nemtsov et al. (2019, this issue) provides an up-to-date and broad synthesis of the evidence showing the extraordinary role that alcohol has played in determining mortality in Russia. Crucially, it links this with an attempt to understand the simultaneous contribution of government policy and the societal trauma of the collapse of the Soviet Union on patterns of alcohol consumption. Of course, the link between alcohol and mortality in Russia is not a story that started with Gorbachev's anti-alcohol campaign of 1985 . Both the Russian Empire and the Soviet Union experienced high levels of alcohol harm (Andreev et al., 2013; Lisitsin \& Kopyt, 1983).

Much of the evidence linking mortality and alcohol originates from detailed analyses of mortality changes by causes of death starting in the 1990s (Meslé et al., 1994; Shkolnikov et al., 1996). These changes were large in magnitude and very abrupt. The most important indication of the role of alcohol in determining these massive fluctuations in all-cause mortality is that they were most extreme for mortality from external and alcohol-related causes. However, there are two other features that are also of relevance: (a) the fluctuations were largely restricted to ages 15-60 years with maximum amplitudes at ages 30-40 years, and (b) they were of much larger amplitude for men than for women. Importantly, the mortality increase of the 1990s looked almost like a mirror image (in terms of its age and causes-of-death structure) of the earlier mortality fall during Gorbachev's anti-alcohol campaign in 1985-1987 (Leon et al., 1997).

The nuanced approach taken by Nemtsov et al. to explain the causes of the underlying variation in alcohol consumption is to be welcomed. These variations cannot be explained by any single factor. As outlined by them, it is due to the joint effect of societal stress, government policy, and the economic situation of the country (Brainerd \& Cutler, 2005; Cornia \& Paniccià, 2000; Walberg et al., 1998). However, regardless of how one understands the inter-relationship of these factors in the 1990s, the net result was the most extreme fluctuations in mortality ever directly observed for a national population that were ultimately driven by social, economic, and political forces.
The strong negative correlation between life expectancy at birth and alcohol discussed by Nemtsov et al. was first published in Russian in July 1994 in a short newspaper article titled, "Zhit' ili pit'?" (“To live or to drink?") (Nemtsov \& Shkolnikov, 1994). Our view is that mortality from alcohol poisoning is the best measure of that component of alcohol consumption in Russia that is most strongly related to the fluctuations in mortality. This simple metric captures the pattern of very heavy episodic alcohol consumption better than the estimated per capita consumption of ethanol. This was demonstrated by the Izhevsk case-control (Leon et al., 2007) and cohort (Tomkins et al., 2012) studies, conducted from 2003 to 2009, that showed a decisive role of hazardous alcohol drinking defined as being drunk for 2 or more days (or "zapoi"), having frequent hangovers, and/or drinking nonbeverage alcohols. This composite variable alone explained more than $40 \%$ of male deaths at ages $25-54$ years. The same studies showed a much weaker association of mortality with the total volume of alcohol consumed.

According to Nemtsov et al., the continuous mortality decrease during the late 2000s and 2010s was determined by alcohol. We think that this is only partly true, but we agree that the decline in the alcohol-related mortality, the alcohol policy measures of 2005-2007, and the favorable changes in the alcohol habits of younger Russians (Radaev \& Roshchina, 2019) have substantially contributed to the overall improvement.

Nemtsov et al. focus only on those causes of death that are alcohol related. However, this overlooks the major issue of mortality from cardiovascular disease (CVD). As we have argued elsewhere (Leon et al., 2010), the totality of the evidence supports the proposition that hazardous alcohol consumption in Russia is an important cause of CVD mortality. During the 1990s and the early 2000s, mortality from CVD remained very high; however, since the mid-2000s, there has been a clear decline that has made an important contribution to the rise in life expectancy. This substantial decline has occurred at all ages. More importantly, it was observed at older ages as well, which had never happened before in Russia. 
We estimate that, between 2005 and 2017, the mortality decrease at ages $65+$ constituted 1.7 years in an 8.9-year rise among men and constituted 2.4 years in a 5.6-year rise among women. Decreasing cardiovascular mortality produced $53 \%$ and $79 \%$ of these contributions among men and women, respectively. Most importantly, however, it has continued to decline steeply despite the fact that the decline in mortality from acute alcohol poisonings (as well as the alcohol consumption) has leveled off. This continued decline in CVD that includes also older ages is the principal reason for the fact that life expectancy continued to improve in the 2010s. Therefore, this latest period marks a weakening of the close link that has been observed between alcohol-related mortality and life expectancy since the mid-1980s. The reasons for this are still not absolutely clear, but increasing investment in detection and treatment of CVD may be a key factor (Shkolnikov et al., 2019).

$$
\begin{array}{r}
\text { Vladimir M. ShKolniKov, Ph.D. }{ }^{a, b, *} \\
\text { DaVID A. LeON, PH.D., }{ }^{a, c} \& \\
\text { InNA Danilova, PH.D. }{ }^{a}
\end{array}
$$

${ }^{a}$ Max Planck Institute for Demographic Research, Rostock, Germany

\author{
${ }^{b}$ Research University Higher School of Economics, \\ Moscow, Russian Federation \\ ${ }^{c}$ London School of Hygiene and Tropical Medicine, \\ London, United Kingdom \\ *shkolnikov@demogr.mpg.de
}

\section{References}

Andreev, E., Bogoyavlensky, D., \& Stickley, A. (2013). Comparing alcohol mortality in Tsarist and contemporary Russia: Is the current situation historically unique? Alcohol and Alcoholism, 48, 215-221. doi:10.1093/ alcalc/ags 132

Brainerd, E., \& Cutler, D. M. (2005). Autopsy on an empire: Understanding mortality in Russia and the former Soviet Union. Journal of Economic Perspectives, 19, 107-130. doi:10.1257/0895330053147921

Cornia, G. A., \& Paniccià, R. (2000). The transition mortality crisis: Evidence, interpretation and policy responses. In G. A. Cornia \& R. Paniccià (Eds.), The mortality crisis in transitional economies (pp. 3-37). Oxford, England: Oxford University Press.

Leon, D. A., Chenet, L., Shkolnikov, V. M., Zakharov, S., Shapiro, J., Rakhmanova, G., . . . McKee, M. (1997). Huge variation in Russian mortality rates 1984-94: Artefact, alcohol, or what? The Lancet, 350, 383-388. doi:10.1016/S0140-6736(97)03360-6

Leon, D. A., Saburova, L., Tomkins, S., Andreev, E., Kiryanov, N., McKee, M., \& Shkolnikov, V. M. (2007). Hazardous alcohol drinking and premature mortality in Russia: A population based case-control study. The Lancet, 369, 2001-2009. doi:10.1016/S0140-6736(07)60941-6

Leon, D. A., Shkolnikov, V. M., McKee, M., Kiryanov, N., \& Andreev, E. (2010). Alcohol increases circulatory disease mortality in Russia: Acute and chronic effects or misattribution of cause? International Journal of Epidemiology, 39, 1279-1290. doi:10.1093/ije/dyq102

Lisitsin, Yu.P., \& Kopyt, N.Ya. (1983). Alkogolozm: Sotsialno-Gigienicheskiye aspekti (Alcoholism: Socio-Hygienic Aspects). Second Edition. Moscow: Meditsina.

Meslé, F., Shkolnikov, V., \& Vallin, J. (1994). Brusque montée des morts violentes en Russie. Population (French Edition), 49, 780-790. doi: $10.2307 / 1533967$

Nemtsov, A., Neufeld, M., \& Rehm, J. (2019). Are trends in alcohol consumption and cause-specific mortality in Russia between 1990 and 2017 the result of alcohol policy measures? Journal of Studies on Alcohol and Drugs, 80, 489-498. doi:10.15288/jsad.2019.80.489

Nemtsov, A., \& Shkolnikov, V. (1994, July 19). Zhit' ili pit?' (To live or to drink?). Izvestiya, 135.

Radaev, V., \& Roshchina, Y. (2019). Young cohorts of Russians drink less: Age-period-cohort modelling of alcohol use prevalence 1994-2016. Addiction, 114, 823-835. doi:10.1111/add.14535

Shkolnikov, V. M., Andreev, E. M., Tursun-zade, R., \& Leon, D. A. (2019). Patterns in the relationship between life expectancy and gross domestic product in Russia in 2005-15: A cross-sectional analysis. The Lancet Public Health, 4, e181-e188. doi:10.1016/S2468-2667(19)30036-2

Shkolnikov, V., Meslé, F., \& Vallin, J. (1996). Health crisis in Russia. II. Changes in causes of death: A comparison with France and England and Wales (1970 to 1993). Population. English Selection, 8, 155-189.

Tomkins, S., Collier, T., Oralov, A., Saburova, L., McKee, M., Shkolnikov, V., , . Leon, D. A. (2012). Hazardous alcohol consumption is a major factor in male premature mortality in a typical Russian city: Prospective cohort study 2003-2009. PLoS One, 7(2), e30274. doi:10.1371/journal. pone. 0030274

Walberg, P., McKee, M., Shkolnikov, V., Chenet, L., \& Leon, D. A. (1998). Economic change, crime, and mortality crisis in Russia: Regional analysis. $B M J, 317,312-318$. doi:10.1136/bmj.317.7154.312 